\title{
LITHUANIAN UNDERGRADUATE STUDENTS' APPROACHES TO LEARNING ENGLISH FOR SPECIFIC PURPOSES
}

\author{
NIJOLĖ BURKŠAITIENĖ \\ Department of Translation Studies, Institute for Literary, Cultural and Trans- \\ lation Studies Faculty of Philology, Vilnius University \\ Universiteto g. 3, LT-01513 Vilnius, Lithuania \\ E-mail address: nijole.burksaitiene@flf.vu.lt \\ ORCID: https://orcid.org/0000-0003-3806-3392 \\ JOLITA ŠLIOGERIENE் \\ Department of Foreign Languages, Faculty Creative Industries \\ Vilnius Gediminas Technical University \\ Saulètekio al.11, LT-10223 Vilnius, Lithuania \\ E-mail address: jolita.sliogeriene@vilniustech.lt \\ ORCID: https://orcid.org/0000-0003-0062-3200
}

\begin{abstract}
Aim. It has been established by research that learners' approaches to learning and to the learning contexts in which the process of learning occurs play a pivotal role at all levels of education. Tertiary students' approaches to learning have been widely investigated across different fields of study, however, little known research has focused on their approaches to learning foreign languages. Thus, to deepen our understanding in this field, the present research aims at establishing undergraduate students' approaches to learning English for Specific Purposes (ESP) in an institution of higher education in Lithuania.

Methods. The investigation was conducted with the participation of 111 undergraduate students, majors in 11 different study programmes, who took a mandatory course in ESP. The data were collected from the structured questionnaires; to carry out the research, quantitative research methods were used.

Results. The research revealed that some students' low engagement in the study process and their intention to learn as much as to get a passing grade was the result of surface approach that they used to learning ESP. The findings also disclosed a positive correlation between the students' organised and systematic learning and planning their study time, which led to the assumption that these students were likely to use a deep approach to learning ESP. Finally, the statistical calculations proved that the students whose approach to learning ESP was deep were able to self-regulate their learning.
\end{abstract}


Conclusion. The main conclusion of this research is that the participants' approaches to learning ESP were both surface and deep. The results also suggested that some students could be directed towards deep learning by fostering their engagement in the study activities.

Key words: approach to learning, deep learning, surface learning, English for Specific Purposes, higher education

\section{INTRODUCTION}

pproaches to learning have been researched since the late 1970s (Marton \& Säljö, 1976; Ramsden, 1987; Entwistle, 1998; Biggs, 1999; Case \& Marshall, 2004; Hay, 2007; Smith \& Colby, 2007; Price, 2011; Trigwell, Ellis, \& Han, 2012; Lindblom-Ylänne, Parpala, \& Postareff, 2019; Tuononen, Parpala, \& LindblomYlänne, 2020). The concept of 'an approach to learning' originally referred to the way in which students (who were under the experiment conditions) carried out a specific learning (reading) task (Marton \& Säljö, 1976, as cited in Ramsden, 1987). Later, in the 1980s, researchers started to explore how students approached the whole course, therefore, since then the concept has been used to describe the way students learn in relationship to a learning context and their response to that learning context (Case \& Marshall, 2004; Turner \& Baskerville, 2013).

It has been reported in the literature that students' approaches to learning can be surface, deep or achieving (also called strategic). The first approach means that the student seeks to fulfil a given assignment or meet the requirements of the course (in order to pass the examination) without considering or questioning much what is being learnt. This approach is associated with routine memorisation or reproduction of material, which results in fragmented learning outcomes and the lack of conceptual understanding of what was learnt (Entwistle, 1998; Beattie IV, Collins, \& McInnes, 1997; Biggs, 1999; Hall, Ramsey, \& Raven, 2004; Struyven, Dochy, \& Janssens, 2005; LindblomYlänne, Parpala, \& Postareff, 2019; Tuononen, Parpala, \& Lindblom-Ylänne, 2020). Recently, the term 'unreflective approach' has been introduced "to more deeply describe the surface approach in the $21^{\text {st }}$ century, taking into account an unreflective study process and the inability to form a coherent whole of the subject" (Lindblom-Ylänne, Parpala, \& Postareff, 2018, as cited in Tuononen, Parpala, \& Lindblom-Ylänne, 2020, p. 1082).

In contrast, deep approach to learning is described as the approach adopted by the students who are actively engaged in the learning process. They seek to understand what is being learnt and to see the phenomena that are being analysed in a wider context. Therefore, such learning is meaningful and generally results in high-quality learning outcomes that constitute deep understanding and educative conceptual change (Entwistle, 1998; Biggs, 1999; Struyven, Dochy, \& Janssens, 2005).

The third approach to learning is the achieving or strategic approach introduced by John Biggs (1979) and Paul Ramsden (1979) (as cited in Entwistle, 1998, p. 73). The students who use this approach seek the highest grades. To 
this end, they organise their learning so that to align it with the requirements they have to meet in order to achieve their goal. This can result in the award of high grades with little or with limited understanding of what was learnt (Entwistle, 1998; Struyven, Dochy, \& Janssens, 2005).

Students' approaches to learning have been extensively researched across different fields of study, including accounting (e.g., Hall, Ramsey, \& Raven, 2004; Turner \& Baskerville, 2013; Philipps \& Graeff, 2014), engineering (e.g., Case \& Marshall, 2004), biology (e.g., Trigwell, Ellis, \& Han, 2012; Tal \& Tsaushu, 2018), and epidemiology (e.g., Filius et al., 2018), etc. Research evidence suggests that students' views of assessment requirements play an important role regarding their choice of an approach to learning (Ramsden, 1987; Struyven, Dochy, \& Janssens, 2005). Thus, for instance, strategic learners can shift from deep to surface approach in those cases where assessment requirements lead to memorisation. On the other hand, students whose approach to learning is deep can use memorisation to reinforce understanding, which does not constitute surface approach to learning as their goal is still to understand (Entwistle, 1998). Besides, it has been reported that the learning environment, including teaching methods, curricula, assessment methods and institutional atmosphere, also influence students' approaches to learning (Hall, Ramsey, \& Raven, 2004; Case \& Marshall, 2004; Sherer \& Shea, 2011; McDowell et al., 2011; Turner \& Baskerville, 2013; Phillips \& Graeff, 2014; Filius et al., 2018; Tal \& Tsaushu, 2018; Lindblom-Ylänne, Parpala, \& Postareff, 2019).

Literature overview demonstrates that little known research has focused on students' approaches to learning foreign languages at the university in general and, in particular, on students' approaches to learning ESP. Investigating this issue would deepen ESP teachers' understanding of their students' views regarding the discipline, which would enable them to support those students who may need some guidance towards a deep approach. To contribute to the research in this field, the present research was conducted at a university in Lithuania. It explored approaches to learning ESP used by 111 undergraduate students' (majors in 11 study programmes) in mandatory ESP courses that were in line with their discipline. The data for the present research were drawn from the structured questionnaires. The present study starts with an overview of the relevant literature which reports on previous investigations in the field. The research methodology as well as research limitation are then discussed. Finally, the results of this study are reported, and conclusions drawn. To conduct the research, a quantitative methodology is used.

\section{LITERATURE OVERVIEW}

The literature overview shows that the most recent research has been focused on the learning environment and its impact on students' approaches to learning (Hall, Ramsey, \& Raven, 2004; Case \& Marshall, 2004; Sherer \& Shea, 2011; McDowell et al., 2011; Turner \& Baskerville, 2013; Phillips \& Graeff, 2014; Filius 
et al., 2018; Tal \& Tsaushu, 2018; Lindblom-Ylänne, Parpala, \& Postareff, 2019). It has been established that the instructional change from teacher-centred teaching to student-centred learning influences students' approach to learning. To illustrate, Tali Tal and Masha Tsaushu (2018) introduced individual learning and project-based learning in an undergraduate lecture-based biology course. The shift produced evidence for deep learning, including producing student-generated ideas, asking meaningful questions and connecting new knowledge to knowledge of their own field. Similar findings were reported by investigations conducted in accounting studies (Hall, Ramsey, \& Raven, 2004; Phillips and Graeff, 2014; Turner and Baskerville, 2013). For example, Matthew Hall, Alan Ramsey and John Raven (2004) found that the introduction of group-based problem-solving activities in an introductory financial accounting course reduced students' surface approach to learning and fostered their deep approach to learning. Similarly, Mary Phillips and Timothy Graeff's (2014) findings showed that an in-class simulation used instead of the traditional lecture format in accounting classes for undergraduate business students helped them to better understand the principles of accounting and created a more positive attitude towards the discipline.

The literature overview also revealed that deep approach to learning can be supported by changes in assessment. For instance, Liz McDowell, Deli Wakelin, Catherine Montgomery and Sara King (2011) investigated the impact of assessment practices on student learning across 14 different modules at a university in the UK. Their findings demonstrated that the module design which included a well-balanced formative and summative assessment and the staff support provided to the study participants were the factors that fostered their deep approach to learning. Along similar lines, Martin Turner and Rachel Baskerville's (2013) findings showed that original assessment tasks tailored in line with accounting students' needs and regular formative and summative feedback provided to them throughout the course supported deep learning.

It has been also reported in the literature that there exist links between students' approaches to learning, their learning outcomes, and their emotional experience. For instance, Keith Trigwell, Robert Ellis and Feifei Han (2012) established that the undergraduate biology students who experienced more positive emotions regarding the course used deep approach to learning. The authors also found that the students whose achievements were high experienced positive emotions regarding the course and used deep approach to learning it. On the other hand, the results also showed that the students whose emotional experiences were negative had low grades and used surface approach to learning. In another study, Tarja Tuononen, Anna Parpala and Sari Lindblom-Ylänne (2020) investigated the relationship between graduate students' approaches to learning and their self-evaluation of the learning outcomes achieved as the result of their university studies. It was found that those students who used deep approach to learning were more organised and self-evaluated their learning outcomes more highly than those who used surface approach.

As little known research has been focused on the ways how university students approach learning English for Specific Purposes, the present research 
aims to fill this gap and to contribute to knowledge in the field by analysing Lithuanian students' approaches to learning this subject.

\section{METHODOLOGY}

The present research aims to establish the ways in which undergraduate students approach learning English for Specific Purposes across 11 mandatory ESP courses that are in line with different subject disciplines. The research was conducted with the participation of 111 first-year undergraduate students (35 males and 74 females) who studied English for Specific Purposes in 11 study programmes at a university in Lithuania.

\section{Methods}

The main research methods used in the present study included the analysis of relevant research literature and quantitative research methods. The first part of the structured questionnaire designed by McDowell, Wakelin, Montgomery and King (2011, p. 752) was used as the instrument used in the study.

The data collected through the structured feedback questionnaires were analysed using the Likert-type scale of measurement and statistical data analysis methods (SPSS version 22), including the analysis of variance (ANOVA) and the statistical analysis for the estimation of correlation between variables (Pearson correlation). To establish the consistency of the questions for the sample, Cronbach alpha coefficient was used, and a high level of internal consistency was established (Cronbach alpha $=0.91$ ).

The participants' demographic data regarding their gender and the study programme were excluded from the calculations as they did not have an internal correlation with or significance to the research results.

\section{Research limitation}

The limitation of the present research is its scope, i.e., the investigation was conducted at one university in Lithuania; therefore, this limitation does not allow for wide-scale generalisations.

\section{RESULTS}

The present research aimed to establish 111 undergraduate students' approaches to learning ESP at the university by exploring their engagement in the study activities, willingness to go beyond the task and the ability to selfregulate their learning. The results indicate that the students demonstrated both surface and deep approaches.

Surface approach to learning ESP was established by analysing the relations between the variables showing the level of difficulty to remember things and willingness to read more than it was required $\left(r=0.201^{*}, p=0.03\right)$. This statistically significant correlation indicated that the students who found difficulties in learning ESP tended to engage in the task only as much as it was needed to cope 
with the task or the course requirements. The research results also revealed that a statistically significant correlation was found between the variables "reading very little" and "studying just for assignments" $\left(r=0.298^{* *}, p=0.002\right)$, suggesting that these students' engagement in the study process was low and that their intention was to learn as much as to get a passing grade.

Another feature of surface learning is memorisation or applying learning methods that do not involve reflection. It has been mentioned above that the term 'unreflective approach' also refers to surface approach. Such an approach was also identified in the present research: a statistically significant correlation was established between the variables "learning without seeing much" and "not related pieces in mind" $\left(r=0.318^{* *}, p=0.001\right)$, indicating that the more unreflective learning is, the more it results in fragmented learning outcomes. The research findings regarding the variables "reading very little" and "not related pieces in mind" $\left(r=0.401^{* *}, p=0.000\right)$ suggest that the less students read for the subject, the more fragmented their learning outcomes are. Thus, it is likely that the students who did not reflect on their learning found it difficult to relate concepts, analyse and synthesise what was learnt.

Surface approach is also characterised by students' attempt to remember facts and details or some bits of information. The research revealed that $38.1 \%$ of the respondents agreed and 9\% strongly agreed with the statement that while learning they focused only on the information that they had to know in order to pass the examination. It was also found that $28.8 \%$ of the respondents agreed and $12 \%$ strongly agreed with the statement that they learnt without questioning much what they were taught, demonstrating that they used surface approach to learning as they did not try to establish the meaning of what was learnt (see Figure 1). Surprisingly, only about $15 \%$ of the responses to this statement were 'disagree' or 'strongly disagree'.

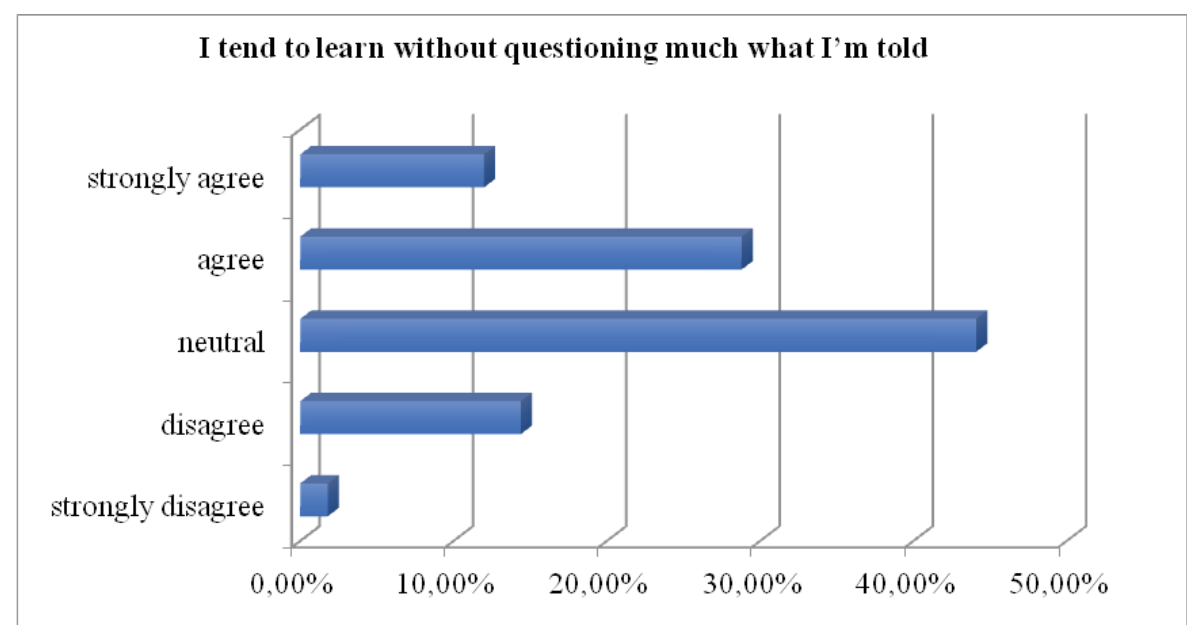

Fig. 1. Students' willingness to question what they were taught Source: the authors' research. 
Analysing students' approaches to learning ESP, their self-regulation was also taken into account with a special focus on one aspect, i.e., their self-pacing in learning. A statistically significant correlation was found between the variables indicating how organised and systematic students were in their studies and how they organised their study time $\left(r=0.304^{* *}, p=0.000\right)$. This finding suggests that the more organised the students were, the more systematic they were in their studying, which leads to an assumption that the students who organised their study time had a tendency to use a deep approach to learning ESP.

Having calculated the percentage for the variables "looking at evidence in order to reach a conclusion," "finding better ways" and "trying a different approach" characterising deep approach towards learning, it was found (see Figure 2) that more than half of the respondents demonstrated their engagement in studies by considering evidence in order to reach a conclusion $(48.2 \%$ agreed and $9.8 \%$ strongly agreed), by trying to find better ways while looking for information (41.21\% agreed and $11.6 \%$ strongly agreed) and by their own initiative to try a different approach if they found it difficult to understand things while learning (46.4\% agreed and $9.8 \%$ strongly agreed).

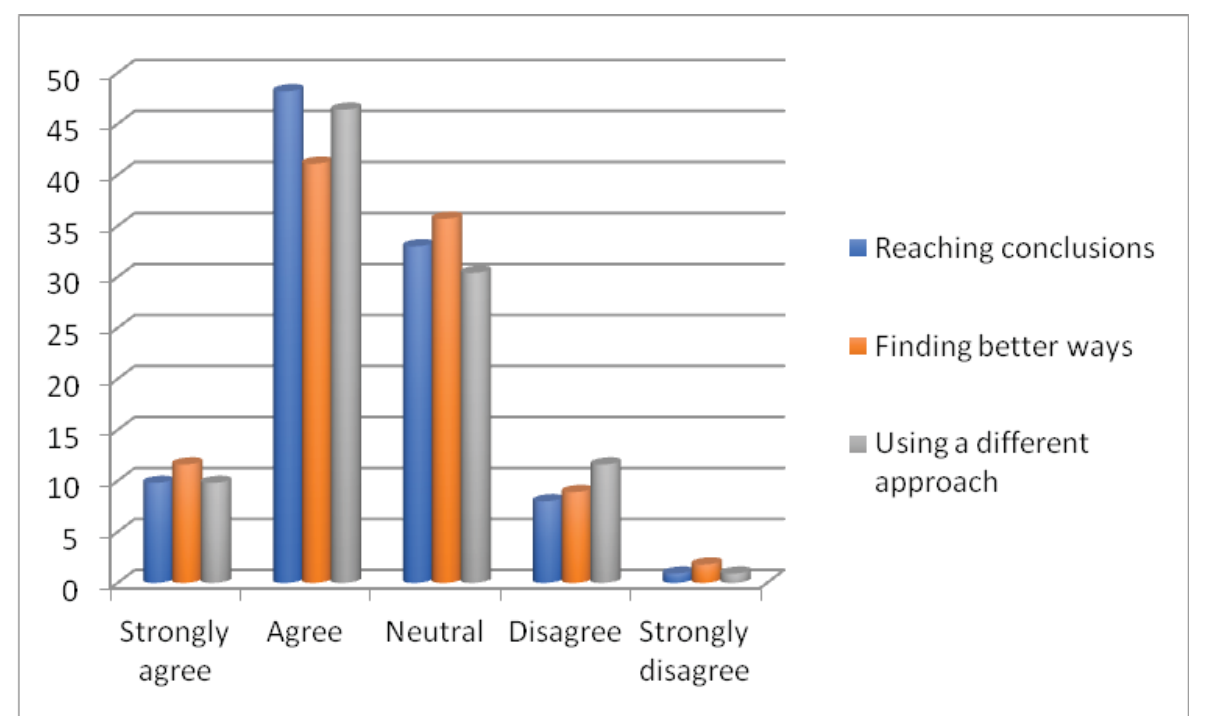

Fig. 2. Variables of deep approach towards learning ESP

Source: the authors' research.

It is also worth noticing that only about $10 \%$ of the respondents strongly disagreed or disagreed with these statements, thus demonstrating that they were not much engaged in searching for different ways of learning or trying a different approach.

To define the statistical validity of differences between deep and surface approaches to learning ESP, the Chi-Quadrate criterion of polynomial distributions was applied. The findings suggest that the values of Chi-Quadrate for 
the group of students who would take a different approach when studying show statistically significant differences. Chi-Quadrate criterion of polynomial distributions demonstrated a statistically significant difference of the results between the students who found it very important to look for arguments or reasons while studying $(x=57.973 ; p=.000)$ and who related ideas to practical situations $(x=62.919 ; p=.000)$. Thus, the statistical calculations proved that the students whose approach to learning ESP was deep were able to self-regulate their studying.

\section{DISCUSSION AND CONCLUSIONS}

The present investigation aimed to establish Lithuanian undergraduate students' approaches to learning ESP at the university by exploring their engagement in the study activities, their willingness to go beyond the task and the ability to self-regulate their studying. The main conclusion of this research is that the participants' approaches to learning ESP were both surface and deep.

More specifically, the findings revealed that while studying ESP almost half of the study participants tried to learn only those bits of information that were required in order to pass, which shows that they used surface approach. This finding was supported by a statistically significant correlation established between the variables showing the level of difficulty to remember things and willingness to read more than it was required for examinations and tasks. The analysis of students' willingness to go beyond the task showed that almost $40 \%$ of students were studying without questioning much what was being taught. This result was supported by the statistically significant correlation between the difficulty students had in understanding where their studying was going and the inability to make a whole picture of the subject (ESP). These findings are in line with the definition of surface approach provided by many researchers (Entwistle, 1998; Beattie IV, Collins, \& McInnes, 1997; Trigwell, Ellis, \& Han, 2012).

On the other hand, the analysis of variables regarding students' engagement in studying ESP showed that $58 \%$ of study participants studied the evidence carefully before they reached their own conclusions, $52.8 \%$ of them tried to employ better ways while looking for information, and $56.2 \%$ tried a different approach if they did not understand things well enough in the course. These findings were strengthened by statistically significant correlations established between the students' ability to self-regulate their study process and their approaches to learning ESP, which demonstrated their active engagement with the subject (ESP). These results are in accord with the definition of deep approach to learning, which is characterised as meaningful learning and as learning aimed at understanding (Entwistle, 1998; Biggs, 1999; Struyven, Dochy, \& Janssens, 2005).

Finally, since the findings of this research illustrate that a number of students learnt ESP only as much as it was required to meet the requirements of 
the mandatory course and to pass the examination, it is recommended to guide them towards deep learning by supporting them and fostering their engagement in the course. The relevant research suggests that this can be achieved by introducing group-based and individualised learning (Hall, Ramsey, \& Raven, 2004; Tal \& Tsaushu, 2018), by providing students with regular formative and summative feedback (Turner \& Baskerville, 2013) and with teacher support (McDowell et al., 2011).

The present research is novel as it is one of the first investigations in Lithuania which focuses on undergraduate students' approaches to learning ESP. The study contributes to the literature as it increases our understanding of the approaches that students enrolled in different Bachelor programmes representing different disciplines use while learning ESP at the university.

\section{REFERENCES}

[1] Beattie IV, V., Collins, B., \& McInnes, B. (1997). Deep and surface learning: a simple or simplistic dichotomy? Accounting Education, 6(1), 1-12. doi:10.1080/ /096392897331587.

[2] Biggs, J. (1999). What the student does: teaching for enhanced learning. Higher Education Research $\mathcal{E}$ Development, 18(1), 57-75.

[3] Case, J., \& Marshall, D. (2004). Between deep and surface: procedural approaches to learning in engineering education contexts. Studies in Higher Education, 29(5), 605-615. doi:10.1080/03 07507042000261571.

[4] Entwistle, N. (1998). Approaches to learning and forms of understanding. In: B. Dart \& G. Boulton-Lewis (Eds.), Teaching and learning in higher education: From theory to practice (pp. 72-101). Melbourne: Australian Council for Educational Research.

[5] Filius, R. M., de Kleijn, R. A. M., Uijl, S. G., Prins, F. J., van Rijen H. V. M., \& Grobbee, D. E. (2018). Strengthening dialogic peer feedback aiming for deep learning in SPOCs. Computers $\mathcal{E}$ Education, 125(2018), 86-100.

[6] Hall, M., Ramsey, A., \& Raven, J. (2004). Changing the learning environment to promote deep learning approaches in first-year accounting students. Accounting Education, 13(4), 489-505. do i: $10.1080 / 0963928042000306837$.

[7] Hay, D. B. (2007). Using concept maps to measure deep, surface and non-learning outcomes. Studies in Higher Education, 32(1), 39-57. doi:10.1080/03075070601099432.

[8] Lindblom-Ylänne, S., Parpala, A., \& Postareff, L. (2019). What constitutes the surface approach to learning in the light of new empirical evidence? Studies in Higher Education, 44(12), 21832195. doi:10.1080/03075079.2018.1482267.

[9] McDowell, L., Wakelin, D., Montgomery, C., \& King, S. (2011). Does assessment for learning make a difference? The development of a questionnaire to explore the student response. Assessment \& Evaluation in Higher Education, 26(7), 749-765. doi:10.1080/02602938.2010.488792.

[10] Philips, M. E., \& Graeff, T. R. (2014). Using in-class simulation in the first accounting class; moving from surface to deep learning. Journal of Education for Business, 89(5), 241-247. doi:10. 1080/08832323.2013.863751.

[11] Price, L. (2011, December 1-2). Modelling factors for predicting student learning outcomes in higher education [Conference presentation]. Learning in transition: dimensionality, validity and development scientific research network conference, 1-2 December 2011, University of Antwerp, Belgium.

[12] http://www.ua.ac.be/main.aspx?c=.LEARNINGINTRANSITION\&n=92385

[13] Ramsden, P. (1987). Improving teaching and learning in higher education: The case for a relational perspective. Studies in Higher Education, 12(3), 275-286. doi:10.1080/0307507871233137 8062.

[14] Sherer, P., \& Shea, T. (2011). Using online video to support student learning and engagement. College Teaching, 59 (2), 56-59. 